\title{
Use of magnetic resonance image registration to estimate displacement in the human earcanal due to the insertion of in-ear devices
}

\author{
Simon Benacchio, ${ }^{1, a)}$ Olivier Doutres, ${ }^{1}$ Arthur Varoquaux, ${ }^{2, b)}$ Éric Wagnac, ${ }^{1}$ \\ Arnaud Le Troter, ${ }^{2, b)}$ Virginie Callot, ${ }^{2, b)}$ and Franck Sgard ${ }^{3}$ \\ ${ }^{1}$ Department of Mechanical Engineering, École de Technologie Supérieure (ÉTS), 1100 Rue Notre-Dame O, \\ Montréal, Québec, H3C 1K3, Canada \\ ${ }^{2}$ Aix Marseille Université, CNRS, CRMBM, UMR 7339, Marseille, France \\ ${ }^{3}$ Institut de recherche Robert-Sauvé en santé et sécurité du travail, 505 Boulevard de Maisonneuve O, \\ Montréal, Québec, H3A 3C2, Canada
}

(Received 27 February 2019; revised 12 August 2019; accepted 3 September 2019; published online 15 October 2019)

\begin{abstract}
In-ear devices are used in a wide range of applications for which the device's usability and/or efficiency is strongly related to comfort aspects that are influenced by the mechanical interaction between the device and the walls of the earcanal. Although the displacement of the earcanal walls due to the insertion of the device is an important characteristic of this interaction, existing studies on this subject are very limited. This paper proposes a method to estimate this displacement in vivo using a registration technique on magnetic resonance images. The amplitude, the location and the direction of the earcanal wall displacement are computed for four types of earplugs used by one participant. These displacements give indications on how each earplug deforms the earcanal for one specific earcanal geometry and one specific earplug insertion. Although the displacement due to a specific earplug family cannot be generalized using the results of this paper, the latter help to understand where, how much, and how each studied earplug deforms the earcanal of the participant. This method is revealed as a promising tool to investigate further acoustical and physical comfort aspects of in-ear devices. (C) 2019 Acoustical Society of America. https://doi.org/10.1121/1.5126857
\end{abstract}

Pages: 2452-2465

\section{INTRODUCTION}

In-ear devices (IEDs) such as hearing protectors, hearing aids, or earbuds are used in a wide range of applications. IEDs exert a mechanical static pressure (SMP) on the earcanal walls that both acoustically seal the earcanal from external noise and ensure its stability inside the earcanal. This SMP is pointed out regularly as one of the most direct causes of physical discomfort due to IED insertion (Wheeler and Glorig, 1956; Brown-Rothwell, 1986; Casali et al., 1987; Kochkin, 2000; Gerges and Casali, 2007; Baker et al., 2010; Terroir et al., 2017; Doutres et al., 2019), which hinders a correct and consistent use of the device. It is necessary to assess the SMP in order to control it during the IED design phase: SMP should not be too low to not induce acoustic leaks and it should not be too high to not ignite physical discomfort. Unfortunately, SMP has never been assessed in vivo either by direct or indirect techniques according to the authors' knowledge. Direct methods would require mechanically transparent pressure sensors to be placed between the IED and the earcanal skin. Some indirect techniques based on numerical tools would require the knowledge of the displacement exerted by the IED on the earcanal walls, in addition to the properties of the tissues surrounding

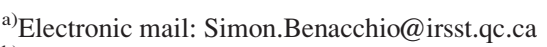

b) Also at: APHM, Hôpital de la Timone, Pôle d'imagerie médicale, CEMEREM, Marseille, France.
}

the earcanal. This work focuses on the estimation of the displacement exerted by IEDs on the earcanal, which could be used as an indirect technique for assessing SMP.

The displacement of the earcanal walls corresponding to the difference of geometry between the open and occluded ear is difficult to measure quantitatively even though it has already been studied qualitatively (Wheeler and Glorig, 1956). Indeed, when the ear is occluded, the presence of the IED prevents the use of classic techniques usually employed to assess the geometry of the open earcanal (Zemplenyi et al., 1985; Rasetshwane and Neely, 2011). For example, optical scanners used to obtain the open earcanal shape cannot be used when the latter is occluded. The well-known ear impression technique is also not suitable to evaluate the shape of the earcanal occluded by an IED. Although this technique is used to manufacture custom molded earplugs and hearing aids (Pirzanski et al., 2000; Pirzanski and Berge, 2004) or to evaluate morphological earcanal differences in intra and intersubject studies (Oliveira, 1997; Grenness et al., 2002; Paulsen et al., 2002; Darkner et al., 2007; Delnavaz and Voix, 2013), it is known to give only an approximate shape of the open earcanal. Indeed, this shape might be deformed by the silicone used to make the impression depending on its viscosity and by motions of the mouth when the user is speaking or chewing (Pirzanski and Berge, 2004; Oliveira et al., 2005). One way to overcome these issues is to use medical imaging techniques (Oliveira et al., 1992; Oliveira, 1997; Inoue et al., 2011; Darkner et al., 2017) whose main advantages are the 
possibilities of obtaining (i) images of both an open and occluded earcanal without applying additional displacements on it and (ii) images of the tissues surrounding the earcanal such as soft tissues (i.e., skin, fat, muscles, etc.), cartilage, or bones, depending on the imaging technique modality. Several studies have already used medical imaging techniques to investigate the earcanal anthropometry (Egolf et al., 1993; Yu et al., 2015; Darkner et al., 2017) or to study the influence of the jaw motion on the canal shape (Oliveira et al., 2005). However, none of them have investigated how IEDs affect the earcanal geometry. Benacchio et al. (2018) recently proposed a method based on a common image processing tool to assess the earcanal displacement field from medical images of both open and occluded earcanals. The aforementioned tool, called the image registration method, had already been used in the past to compute the deformation of the earcanal due to the opening of the mouth (Darkner et al., 2007; Darkner et al., 2008) and to obtain an average earcanal geometry extracted from 45 human earcanal magnetic resonance (MR) images (Darkner et al., 2017). Contrary to previous studies (Oliveira et al., 1992; Pirzanski, 2006) where the magnitude of the displacement was determined only at some specific anatomical landmarks or in planes corresponding to cross sections of the earcanal, the method proposed by Benacchio et al. (2018) provides the displacement vector field (both magnitude and direction) of the entire earcanal wall. In this later work, it was shown that the method enables the estimation of the amplitude of the displacement and of its location with an accuracy of $+/-0.2 \mathrm{~mm}$ and $+/-0.4 \mathrm{~mm}$, respectively, when the displacement is larger than $+/-0.3 \mathrm{~mm}$. This study also demonstrates that the inter-operator variability inherent to the method affects the results only slightly. However, the proposed method was validated on an artificial ear using microcomputed tomography images. Among imaging technique modalities, the magnetic resonance imaging (MRI) seems more interesting to study the earcanal displacement of a human subject since (i) it is a non-invasive method, (ii) it is able to give a good contrast between tissues (depending on the parameters of the sequence), and (iii) it now offers an acceptable image quality and resolution as compared to earlier studies (Oliveira et al., 1992; Oliveira, 1997). Although a preliminary investigation on MRI-like images has given satisfactory results (Benacchio et al., 2018), the proposed method must still be investigated in the case of MR images of the human earcanal collected in vivo.

This paper aims to investigate the possibilities offered by the method previously proposed by the authors (Benacchio et al., 2018) for computing the displacement vector field (called displacement in this paper for the sake of simplicity) applied to the earcanal of a human subject. An adapted MRI sequence was performed to obtain the images of both the open and occluded ears of the participant wearing different types of IEDs (custom molded, roll-down foam, push-to-fit, and premolded earplugs). Results showing the displacement computed using rigid and deformable registrations are presented for each occlusion case.

The paper is organized as follows. In Sec. II, information about the participant and about the four earplug types used in this study are given. Then, details about the imaging and registration steps are presented. Graphical representations are proposed to facilitate the interpretation of the results. In Sec. III, the displacements obtained for the four occlusion cases are presented. Similarities and differences observed between the left and the right ear of the participant are described. These results are discussed and analyzed in Sec. IV and the abilities offered by the proposed method and its limits are finally pointed out.

\section{MATERIALS AND METHODS}

\section{A. Participant}

Since the aim of this work was to demonstrate that the proposed method can be applied to images collected in vivo, a single participant was considered in this study. The participant is a healthy male volunteer, 29 years old. He was eligible according to the criteria of the ethics protocol number H20161101 (ethic comity of the École de technologie supérieure). The inclusion criteria defined in this protocol included an otoscopic examination to ensure that the participant's earcanals were not damaged or occluded by cerumen.

\section{B. Earplugs}

In order to compute the displacement applied by different kinds of in-ear devices, four types of earplugs selected from four earplugs families [custom molded, roll-down foam, push-to-fit, and premolded; see Fig. 1(a)] were considered to occlude the participant's left [see Fig. 1(b)] and right [see Fig. 1(c)] ear. Note that pictures of the right ear have been horizontally flipped to have the same orientation as the left ear. Although different kinds of earplugs are tested here, it should be recalled that this study is not intended to give general results on the displacement due to a specific earplug family or another but to investigate the abilities of the proposed method used in vivo.

The custom molded earplugs tested in this study are depicted in Fig. 1(a.1). They were molded from ear impressions of the participant using biocompatible silicone. It should be noted that the earplug manufacturer was asked to manufacture "large" and "long" custom molded earplugs to ensure acoustic sealing and hold in place, thus leaving aside aspects of physical comfort. The resulting earplugs are not necessarily representative of custom molded earplugs. A rough approximation of the length of the custom earplugs is $30 \mathrm{~mm}$ and their insertion is considered as standard since their shape fits the geometry of the ears.

Roll-down foam earplugs are made of soft closed-cell foam and have a cylindrical initial shape that does not correspond to the earcanal geometry before being inserted. They must be rolled between fingers and compressed into a tight cylinder before insertion. The slow-recovery foam then expands in the earcanal. The roll-down foam earplugs tested in this study are the foam $E-A-R$ Classic earplugs from $3 \mathrm{M}$ (Maplewood, MN) and are shown in Fig. 1(a.2). The length of these earplugs is approximately $19 \mathrm{~mm}$ and their insertion depth is considered as standard [see Figs. 1(b.2) and 1(c.2)] according to Berger (2013), which means that approximately 


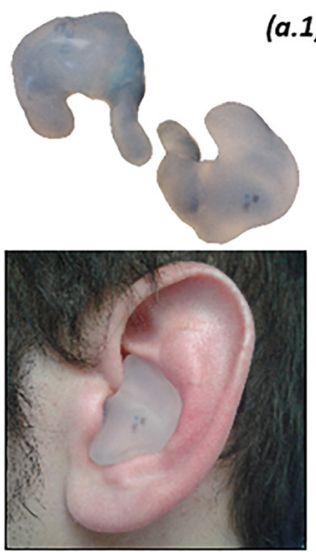

(b.1)

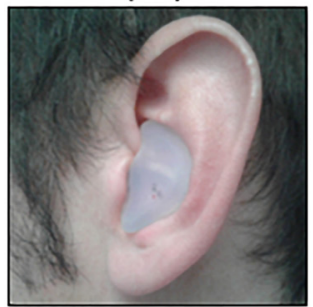

(c.1) (a.1)
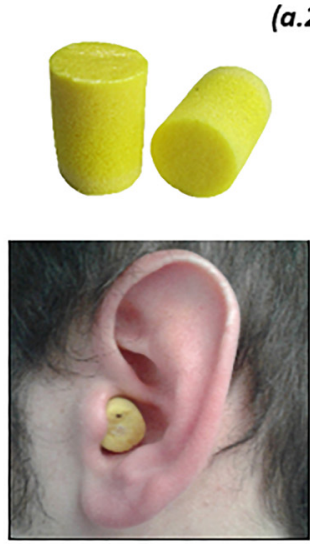

(b.2)

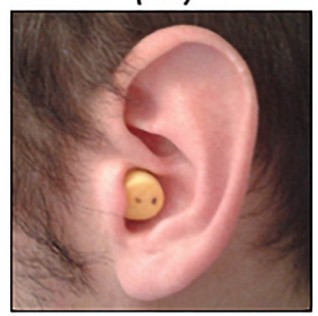

(c.2) (a.2)
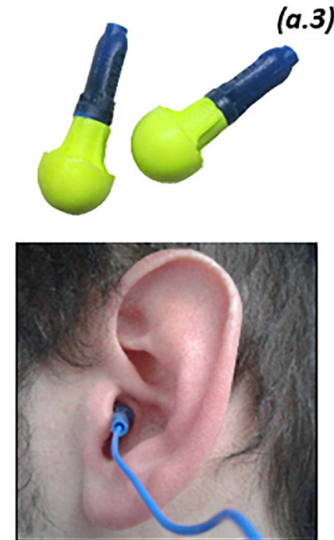

(b.3)

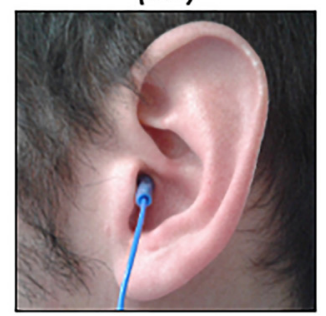

(c.3)
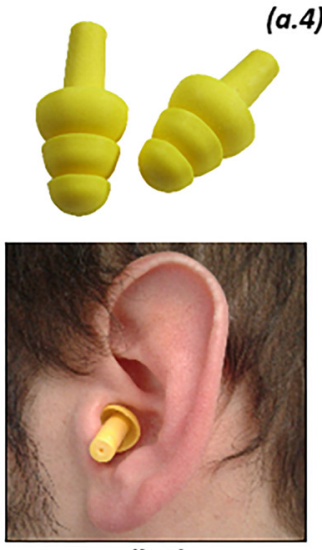

(b.4)

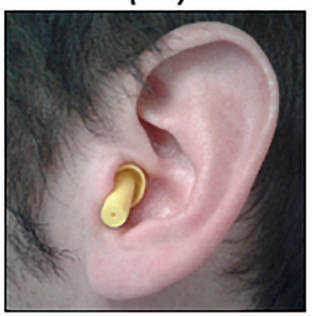

(c.4)

FIG. 1. (Color online) Pictures of (a) earplugs and (b) left and (c) right ears occluded by the (1) custom molded, (2) roll-down foam, (3) push-to-fit, and (4) premolded earplugs. Pictures of the right ear are horizontally flipped to have the same orientation as the left ear.

$50 \%-60 \%$ of the earplug is in contact with the earcanal walls.

Push-to-fit earplugs are made of a plastic rigid stem terminated with a spherical foam (polyurethane) tip. This tip is deformed when inserted in the earcanal and is used to create the acoustic seal between the eardrum and the outside of the ear. The push-to-fit earplugs tested in this study are the E-A-R Push-Ins earplugs from $3 \mathrm{M}$ and are shown in Fig. 1(a.3). The length and diameter of the foam tip are approximately 9 and $12 \mathrm{~mm}$, respectively. The insertion depth is considered deep since the entire tip of the earplug is inside the earcanal and is not visible in Figs. 1(b.3) and 1(c.3).

The premolded earplugs are made of silicone (elastomer polymer) with a 30-mm long cylinder and three flanges at one end, whose diameter progressively increases in size from the one situated at the tip to the one more distal from the tip. Those tested in this study are the E-A-R UltraFit earplugs from $3 \mathrm{M}$ and are shown in Fig. 1(a.4). The length of the earplug section occupied by the three flanges and used to produce the acoustic seal in the earcanal is approximately $16 \mathrm{~mm}$. The smallest flange has a diameter of $8 \mathrm{~mm}$ and the largest one has a diameter of $13 \mathrm{~mm}$. The insertion depth has been chosen so that the first and second flanges are completely inside the earcanal [see Figs. 1(b.4) and 1(c.4)].

These earplugs were inserted by the participant and were visually controlled by an otolaryngologist before starting the measurements. It should be mentioned that earplugs can be inserted in several ways. In the present study, only one insertion for each earplug is investigated and may be different for the left and right ear. Thus, the results presented in Sec. III are inherently dependent on the way the earplugs were inserted despite the visual control of the otolaryngologist.

\section{Imaging}

\section{MR acquisition}

Acquisitions of the whole head of the participant were performed on a Siemens 3 Tesla (Verio) MR system using a 32channel head radio-frequency coil. A Space three-dimensional (3D) T1-weighted sequence (Sampling Perfection with Application optimized Contrasts using different flip angle Evolution) has been adapted to obtain a contrast and a resolution allowing to observe the deformation of earcanals due to the insertion of earplugs. Details of this sequence are given in Table I and resulting images are presented in Fig. 2.

The right half of the axial view of the participant's head is shown in Fig. 2(a). In this figure, the ears of the participant are occluded with the silicone custom molded earplugs. The red rectangle shows the region of interest (ROI) used later to perform the deformable registration and presented in Fig. 2(b). The corresponding ROI for the open ear is given in Fig. 2(c). Numbers on Figs. 2(b) and 2(c) correspond respectively to (1) the air, (2) the soft tissues, (3) the temporal bone, (4) the earplug, and (5) the skin inside the earcanal. It is worth mentioning that Fig. 2(b) shows two parts of the custom molded earplug separated by soft tissues [see number 4 in Fig. 2(b)]. Unfortunately, the axial cutting plane chosen to reveal the end of the earcanal does not make it possible to observe simultaneously this zone and an entire section of the earplug because of the curved shape of the earcanal. Axial slices using another cutting plane and showing the subject's earcanal occluded by other earplugs are presented in the Appendix. 
TABLE I. Imaging parameters of the sequence used to image the earcanal of the participant.

\begin{tabular}{lccc}
\hline \hline Plane & $\begin{array}{c}\text { Repetition / Echo time } \\
(\mathrm{ms})\end{array}$ & $\begin{array}{c}\text { Resolution } \\
(\mathrm{mm})\end{array}$ & Matrix acquisition \\
\hline Axial & $600 / 15$ & 0.6 isotropic & $348 \times 384$ \\
\hline \hline
\end{tabular}

\section{Noise measurement in the MR environment}

Since the non occluded ear images are used as reference in the methodology for estimating earcanal displacement induced by the insertion of earplugs, it was also necessary to image the participant's open ears. However, MR systems are known to be noisy environments and it is often necessary to wear hearing protectors during MR imaging (Salvi and Sheppard, 2018). To ensure that the noise level inside the MR system was not too high for the participant during open ear measurement, the sequence was used in a "quiet" operation mode (increased pulse timing and reduced gradient amplitudes and slew rates as compared to normal mode to minimize acoustic noise). Noise level measurements inside the MR system were performed using a remote acquisition system made up of a $1 / 4$ in. Brüel \& Kjær microphone type 4961 inserted in a flexible plastic tube (length and diameter, respectively, equal to 3 and 0.01 meters) whose free end was positioned at the center of the MR coil. This remote system was used to avoid any effect of the high magnetic field on the ferromagnetic parts of the microphone. The measured noise levels were corrected using the transfer function of the flexible tube. These corrected measurements give the actual noise levels that would have been measured directly by a

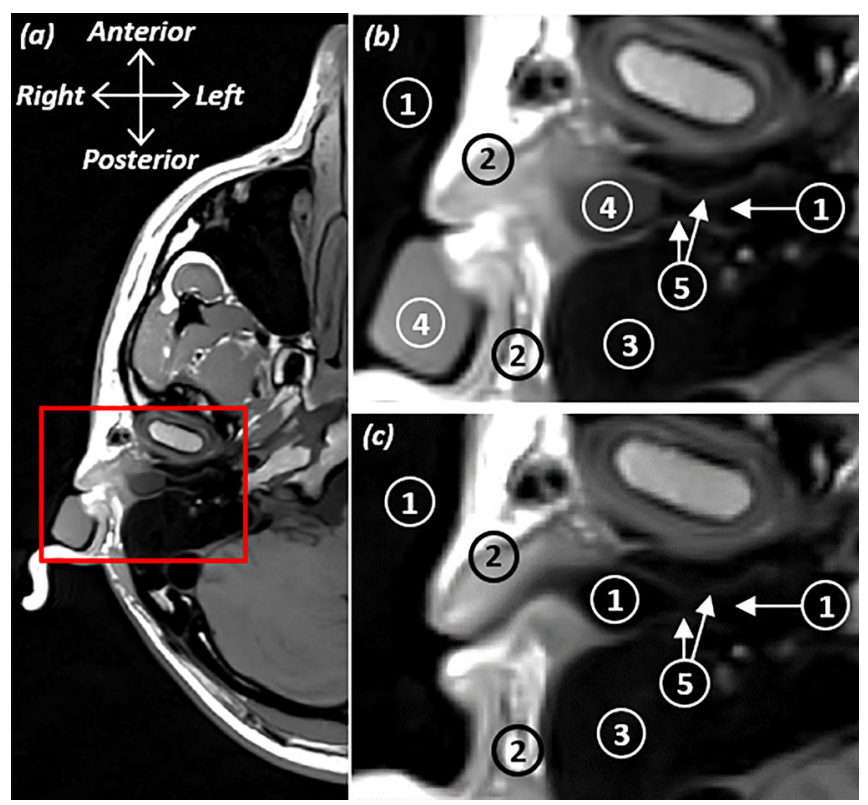

FIG. 2. (Color online) (a) Right half part of the axial view of the participant's head whose ears were occluded by the silicone custom earplugs. The red rectangle gives the extracted ROI localized around the earcanal and represented in (b). The corresponding ROI for the open ear of the participant is given in (c). Numbers give details of the MR image and correspond respectively to (1) the air outside and inside the earcanal, (2) the soft tissues (fat, muscles, cartilage), (3) the temporal bone, (4) the silicone custom earplug, and (5) the skin inside the earcanal. microphone at the center of the MR coil. The noise level inside the coil was $90.9 \mathrm{dBA}$ for the "quiet" sequence and 96.1 dBA for the sequence used in "normal" mode. According to the European regulation (equivalent exposition of $85 \mathrm{dBA}$ for an $8 \mathrm{~h}$ work day), the time allowed for open ear measurements was $2 \mathrm{~h}$ and $2 \mathrm{~min}$ for the "quiet" sequence and $36 \mathrm{~min}$ for the sequence used in "normal" mode. The time allowed for the "quiet" sequence was therefore long enough to image the open ears of the participant without any risk to his health. Note that the "quiet" sequence was also used to image the occluded ears to ensure consistency of measurements.

\section{Measurement procedure}

The MR acquisitions of the participant's right and left earcanals were performed at the same time. First, the participant's non occluded ears were imaged, then the ears were successively imaged when occluded with custom molded, roll-down foam, push-to-fit and premolded earplugs. The participant was asked not to move during each acquisition.

\section{Registration method}

A registration method was used to estimate the deformation of the earcanal induced by the earplug. This method, previously validated for the estimation of an artificial earcanal deformation caused by the insertion of in-ear devices (Benacchio et al., 2018), consists in applying rigid and deformable registrations on medical images using the ANTs library (Avants et al., 2011) details of which can be found in the documentation. ${ }^{1}$ The main steps of the approach are as follows:

\section{Image denoising}

A non-local mean filter is applied to the images using the Denoiselmage function from ANTs. This step improves the discrimination of the tissues surrounding the earcanal (bone and soft tissue).

\section{Over-sampling}

Since a higher image resolution allows a smoother segmentation of the earcanal [see Sec. II D 6)], the images collected here are then over sampled. The resolution of images is empirically multiplied by ten to obtain a voxel size equal to $0.06 \mathrm{~mm}$ isotropic.

\section{Rigid registration}

Rigid registration is used to orient and align images with and without earplugs in the same way. Image of the whole head with open earcanal is used as the target image 
TABLE II. Parameters used for the rigid registration step.

\begin{tabular}{lcccc}
\hline \hline $\begin{array}{l}\text { Transformation } \\
\text { model }\end{array}$ & Similarity metric & $\begin{array}{c}\text { Convergence threshold, } \\
\text { window size }\end{array}$ & $\begin{array}{c}\text { Number of authorized iterations } \\
\text { per level }\end{array}$ & $\begin{array}{c}\text { Shrink factors } \\
\text { per level }\end{array}$ \\
\hline Rigid & Mutual information & $1 \times 10^{-6}, 10$ & 100 & $\begin{array}{c}\text { Sigma of } \\
\text { Gaussian smoothing per level }\end{array}$ \\
\hline
\end{tabular}

for the rigid registration. Images of the whole head with occluded earcanals are used as source images. Parameters of the rigid registration step are given in Table II.

\section{Extraction of the ROI}

In order to focus the computation efforts of the deformable registration on the earcanal displacement estimation, a parallelepipedic area surrounding the earcanal $(41.4 \times 46.2$ $\times 54.2 \mathrm{~mm}$, Coronal $\times$ Axial $\times$ Sagittal $)$ is chosen as region of interest for each ear (see Fig. 2 for example).

\section{Re-orientation of the left ear}

Steps (1) to (4) are performed for images of the entire head of the participant. In order to be able to compare the results from the right and left ears, the two earcanals must have the same orientation. Thus, the extracted ROI of the left ear is reoriented to match that of the right earcanal. First, the images are flipped in the medial/lateral direction (see Fig. 3) and then a rigid registration is applied using the open left earcanal as the source image and the open right earcanal as the target image. Finally, the resulting transformation is applied to the images of the occluded left earcanal.

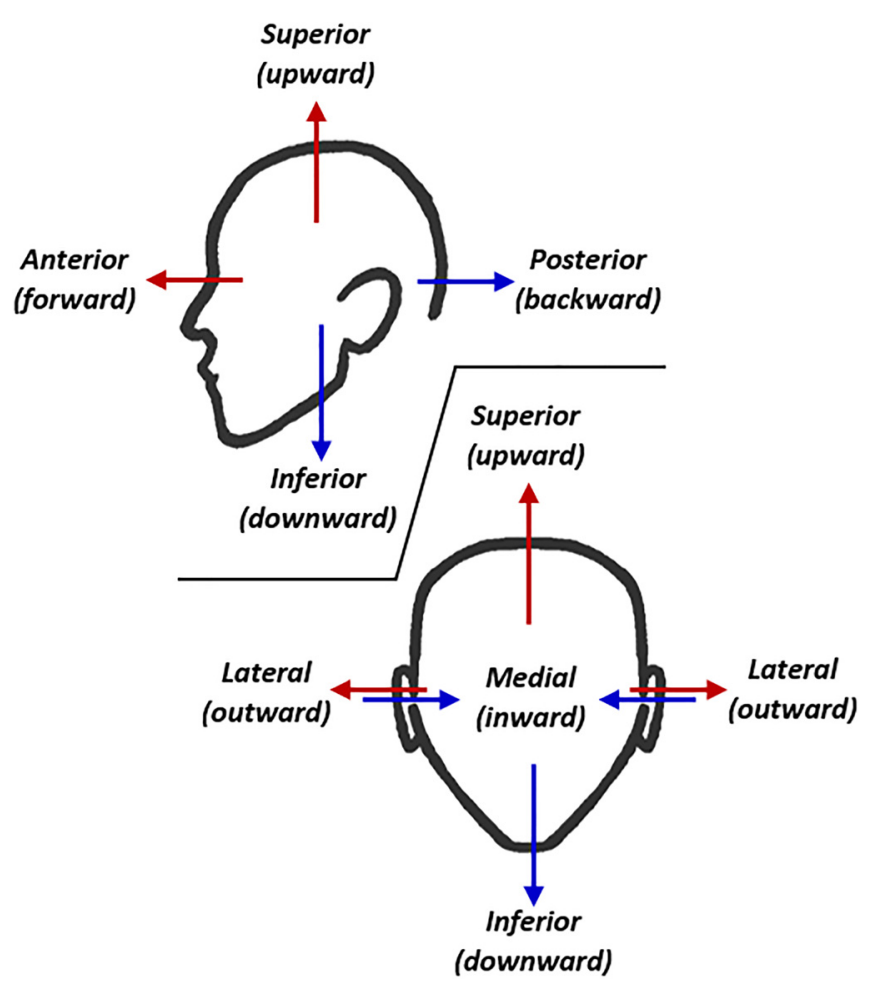

FIG. 3. (Color online) Anatomical directions. The red and blue arrows indicate, respectively, the arbitrary definition of the positive and negative displacements.

\section{Segmentation of the earcanal}

The fact that earplugs appear in images of occluded earcanals but not in images of the open earcanal [see Figs. 2(b) and 2(c)] can lead to registration errors. A segmentation step is therefore performed using the software MIMICS (Materialise, Leuven, Belgium) in order to avoid these errors. The segmentations include the air inside the earcanal for both open and occluded ear images, in addition to the earplug for occluded ear images. The precision and accuracy of this segmentation step has already been tested in Benacchio et al. (2018) and has been shown to be precise and accurate enough to enable the estimation of the displacement of the earcanal walls.

\section{Deformable registration}

A deformable registration is then applied to the segmented images of the occluded ear to estimate the displacement of the earcanal due to the insertion of the earplug. For the right and the left ears, the image of the open ear is used as the source image and the occluded ear is used as the target image. The parameters of the deformable registration step are given in Table III.

\section{E. Accuracy of the computed displacement}

The displacement of the earcanal walls is finally calculated using the transformation computed during the deformable registration step. The accuracy of the estimated displacement is limited by the quality of the images (spatial resolution, contrast-to-noise ratio). Under a certain threshold, referred to as the minimum accuracy level in this paper, the computed estimation of the displacement is no more reliable. This minimum accuracy level was estimated by applying the registration method to a region considered as non deformed and was evaluated to $0.5 \mathrm{~mm}$ for the registration parameters that were utilized and the actual image quality.

\section{F. Graphical representations}

Finally, two complementary graphical representations of the earcanal deformation are proposed. For the first one, only the magnitude of the displacement is displayed. The second representation displays the components of the displacement in the directions presented in Fig. 3. From there, it is therefore possible to determine in which direction the maximum displacement occurs, which is not possible by using only the magnitude of the displacement.

For these components and for both ears, displacements along the superior, anterior, and lateral directions, called upward, forward, and outward, respectively, are considered positive and represented in red in Fig. 3. Displacements along the inferior, posterior and medial directions, referred 
TABLE III. Parameters used for the deformable registration step.

\begin{tabular}{|c|c|c|c|c|c|}
\hline $\begin{array}{l}\text { Transformation } \\
\text { model }\end{array}$ & $\begin{array}{l}\text { Similarity metric, } \\
\text { window radius }\end{array}$ & $\begin{array}{l}\text { Convergence threshold, } \\
\text { window size }\end{array}$ & $\begin{array}{l}\text { Number of authorized } \\
\text { iterations per level }\end{array}$ & $\begin{array}{l}\text { Shrink factors } \\
\text { per level }\end{array}$ & $\begin{array}{l}\text { Sigma of Gaussian } \\
\text { smoothing per level }\end{array}$ \\
\hline $\begin{array}{l}\text { Symmetric } \\
\text { diffeomorphic normalization }\end{array}$ & Cross Correlation, 6 & $1 \times 10^{-6}, 10$ & $\begin{array}{c}100 \times 100 \times 100 \times 100 \times 100 \\
\times 100 \times 100 \times 40\end{array}$ & $\begin{array}{c}10 \times 8 \times 6 \times 5 \times 4 \\
\times 3 \times 2 \times 1\end{array}$ & $\begin{array}{c}10 \times 8 \times 6 \times 5 \times 4 \\
\times 3 \times 2 \times 1\end{array}$ \\
\hline
\end{tabular}

to as downward, backward and inward respectively, are considered negative and represented in blue in Fig. 3. The magnitude together with the component values of the displacement are plotted using a polar representation similar to the one introduced in Benacchio et al. (2018), which gives not only the amplitude of the displacement but also its complete cartography inside the earcanal. This representation is explained in Fig. 4(b).

In Fig. 4, the earcanal is separated in several parts displayed alternatively in white and grey and roughly corresponding to (1) the concha, (2) the first and (3) the second bends, (4) the cartilage/bone junction, and (5) the bony part of the earcanal. Vertical lines in Fig. 4(a) correspond to circular lines in Fig. 4(b) and constitute important landmarks along the earcanal. In Fig. 4(a), transparent red rectangles correspond to areas of the earcanal non-displayed in the polar representation of Fig. 4(b). This latter representation is used to display the earcanal displacement magnitude [see Fig. 5(a.1) for example] and its component values [see Figs. 5(a.2), 5(a.3), and 5(a.4) for example] from $10 \mathrm{~mm}$ from the eardrum [second solid vertical line (from left to right) in Fig. $4(\mathrm{a})]$ to the entrance of the concha located at approximately $35 \mathrm{~mm}$ from the eardrum [last solid vertical line in Fig. 4(a)]. The concha entrance corresponds to the largest circle of the polar plot and the plane located at $10 \mathrm{~mm}$ from the earcanal tip is the center of the polar plot in Fig. 4(b). It is worth mentioning that each colored circle of the polar representation [see Fig. 5(a.1) for example] corresponds to the crosssection between the displacement projected on the earcanal walls and sagittal planes. Compared to the previous study
(Benacchio et al., 2018) the concha is included in the polar representation in addition to the earcanal. Thus, it is also possible to estimate the displacement due to the earplugs in the concha prior to the actual entrance of the earcanal.

In order to help readers to evaluate the amplitude of the maximum displacement magnitude of the earcanal walls, line plots are also displayed. These plots show both the values of the maximum displacement magnitude [see Fig. 5(b.1) for example] and the "maximum" values (both positive and negative) of each component [see Fig. 5(b.2) for example] along the earcanal. These maximum displacement curves are plotted for the sections of the earcanal comprised between the two red rectangles using the same delimitations as those presented in Fig. 4(a).

\section{RESULTS}

In the first part of this section, similar displacement trends computed for left and right ear are described using only the left ear results for illustration. In the second part, the differences observed between the two ears are reported and analyzed using the results of both the left and right ears.

\section{A. Displacement in the left ear}

Results are presented using the two graphical representations described in Sec. IIF. Figures 5, 6, 7, and 8 show the magnitude of the displacement of the left ear together with the value of its components in each anatomical direction (see Fig. 3) for each considered earplug.

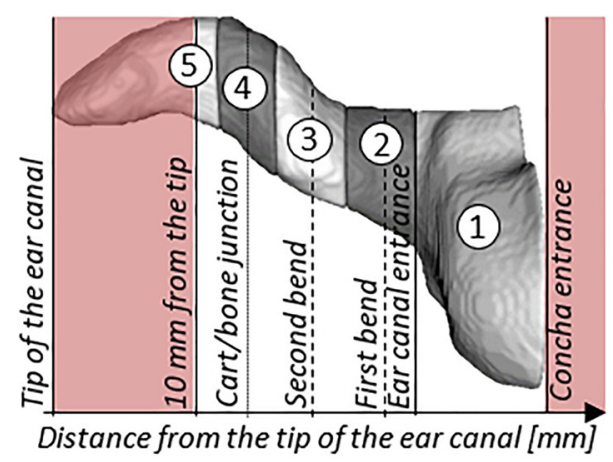

(a)

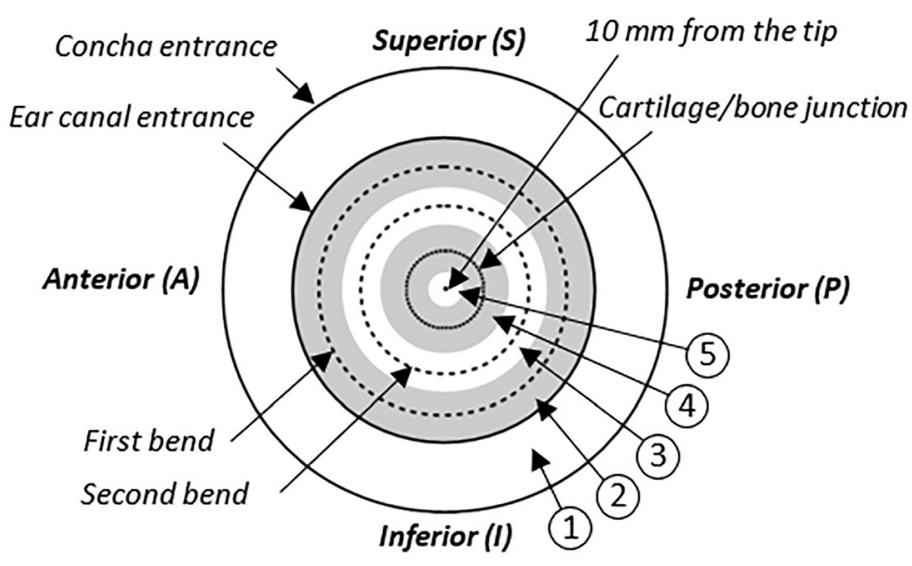

(b)

FIG. 4. (Color online) (a) Coronal view of the right earcanal sectioned to delimit (1) the concha, (2) the first and (3) second bends, (4) the cartilage/bone junction, and (5) the tip of the earcanal. Vertical lines are used to localize the different parts of the earcanal. Transparent red rectangles in (a) correspond to nondisplayed areas in (b). (b) Polar representation used to plot the component values and the displacement magnitude of the earcanal walls. Numbers and circular lines correspond to numbers and vertical lines in (a). 

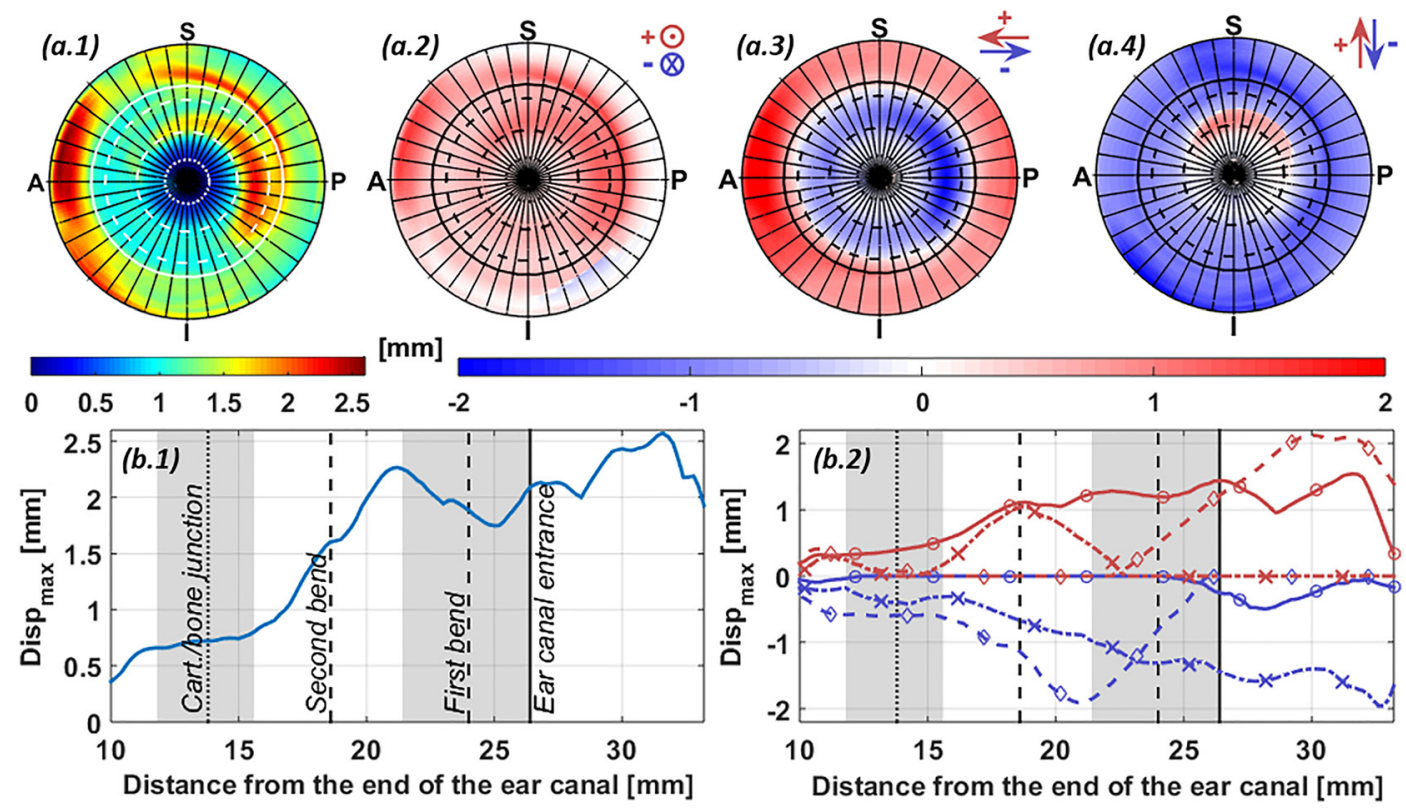

FIG. 5. (Color online) Displacement of the left earcanal occluded by the silicone custom molded earplug. (a) Polar plots and (b) maximum values for (a.1) and (b.1) the magnitude, (a.2) and (b.2) (solid-circle lines) medial/lateral (inward/outward), (a.3) and (b.2) (dashed-diamond lines) posterior/anterior (backward/ forward) and (a.4) and (b.2) (dotted/dashed-cross lines) inferior/superior (downward/upward) components of the displacement.

\section{Custom molded earplugs}

According to Fig. 5(a), the custom molded earplug applies deformations to a long portion of the earcanal. It also pulls the earcanal walls outward overall since the displacement in the medial/lateral direction is positive almost everywhere on the polar plot of Fig. 5(a.2).

From the entrance of the concha to the entrance of the earcanal, the magnitude of the maximum displacement is approximately $2.5 \mathrm{~mm}$ [see Fig. 5(b.1)]. Two parts are mainly deformed in this region [see Fig. 5(a.1)] that is (i) the anterior part of the concha corresponding to the tragus [see
Fig. 1(b.1)], which is mainly deformed forward [see Fig. 5(a.3)] and (ii) a thin region just before the entrance of the earcanal covering its superior/posterior part for which the displacement has an outward [see Fig. 5(a.2)] and downward [see Fig. 5(a.4)] component.

Between the two bends, the posterior part of the earcanal is deformed [see Fig. 5(a.1)] mainly backward [see Fig. 5(a.3)]. The magnitude of the maximum displacement is approximately $2.2 \mathrm{~mm}$ [see Fig. 5(b.1)].

From the second bend to the plane located at $10 \mathrm{~mm}$ from the tip of the eardrum, the earcanal walls are less deformed. From the beginning of the second bend, the displacement
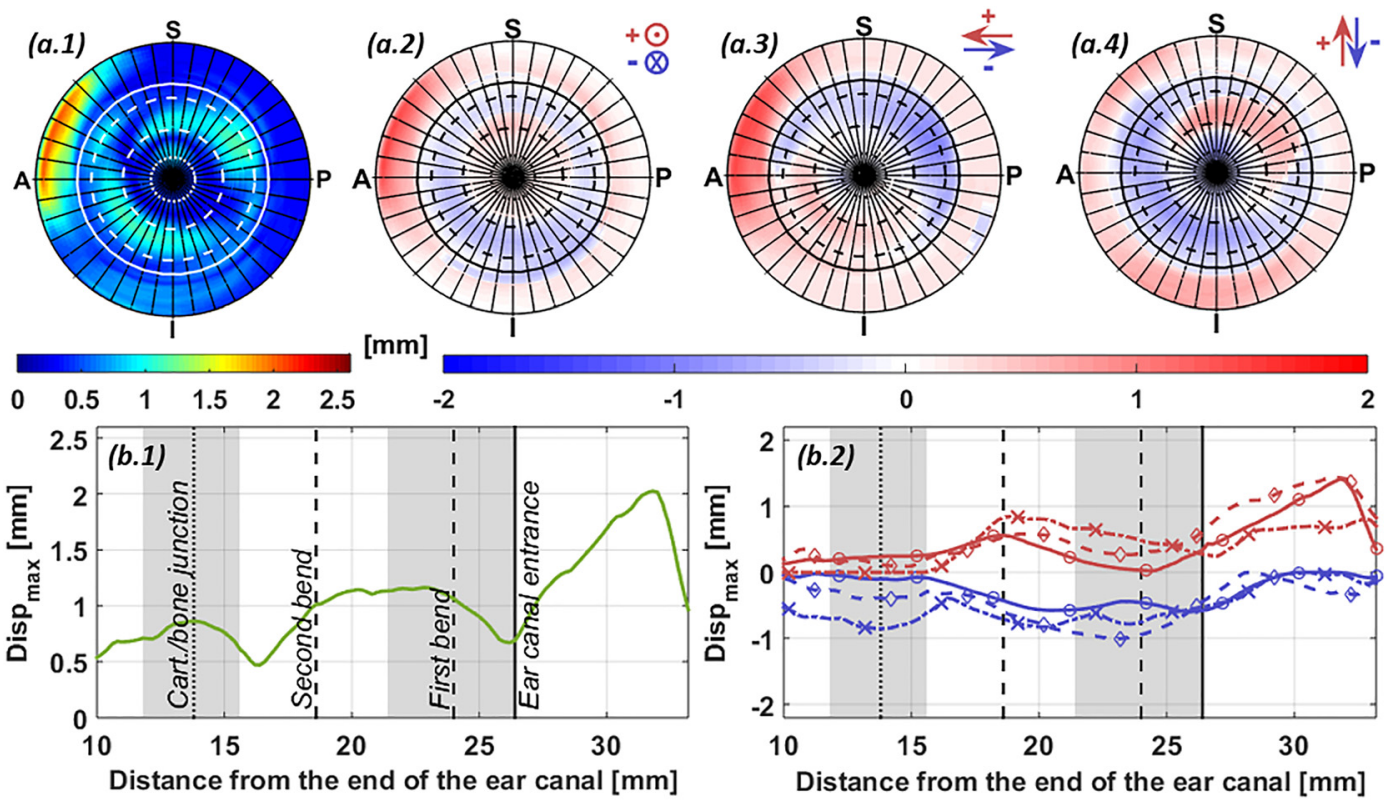

FIG. 6. (Color online) Displacement of the left earcanal occluded by the roll-down foam earplug. (a) Polar plots and (b) maximum values for (a.1) and (b.1) the magnitude, (a.2) and (b.2) (solid-circle lines) medial/lateral (inward/outward), (a.3) and (b.2) (dashed-diamond lines) posterior/anterior (backward/forward) and (a.4) and (b.2) (dotted/dashed-cross lines) inferior/superior (downward/upward) components of the displacement. 

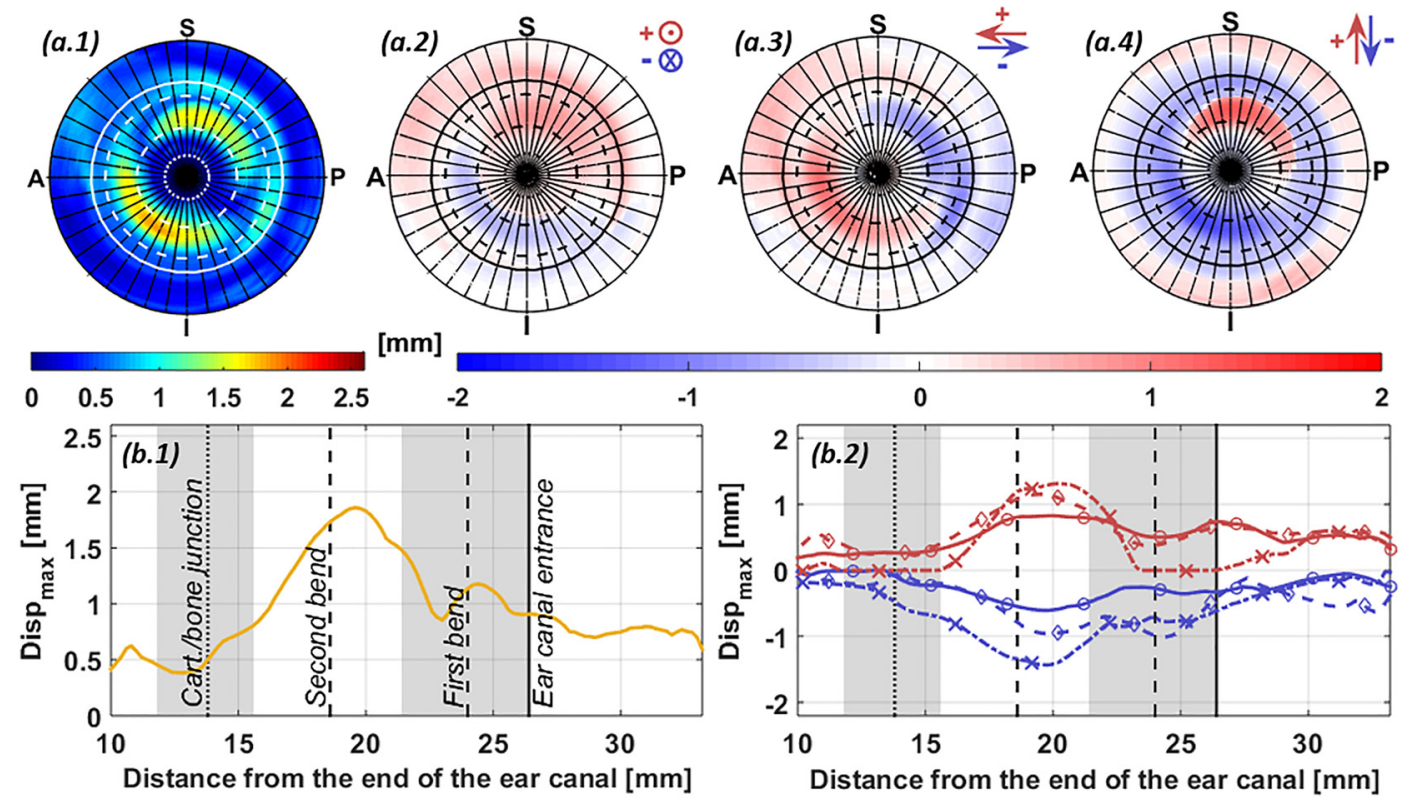

FIG. 7. (Color online) Displacement of the left earcanal occluded by the push-to-fit earplug. (a) Polar plots and (b) maximum values for (a.1) and (b.1) the magnitude, (a.2) and (b.2) (solid-circle lines) medial/lateral (inward/outward), (a.3) and (b.2) (dashed-diamond lines) posterior/anterior (backward/forward) and (a.4) and (b.2) (dotted/dashed-cross lines) inferior/superior (downward/upward) components of the displacement.

magnitude drastically decreases until the entrance of the cartilage/bone junction [see Fig. 5(b.1)] to reach the minimum accuracy level described in Sec. IIE. Thus, the custom earplug does not seem to induce deformation of the earcanal in the inner tip region.

\section{Roll-down foam earplugs}

From the entrance of the concha to the entrance of the earcanal, the roll-down foam earplug deforms the tragus region [see Fig. 6(a.1)].
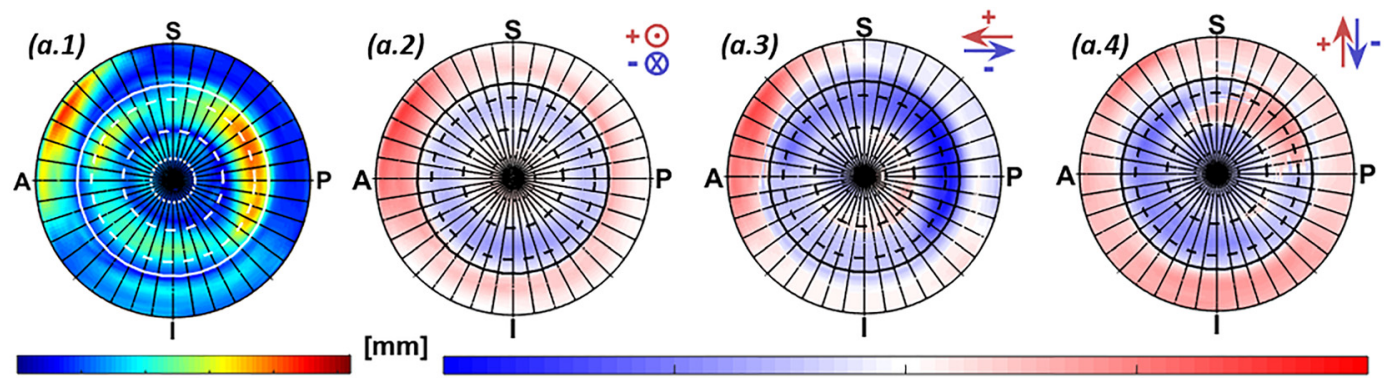

[mm]
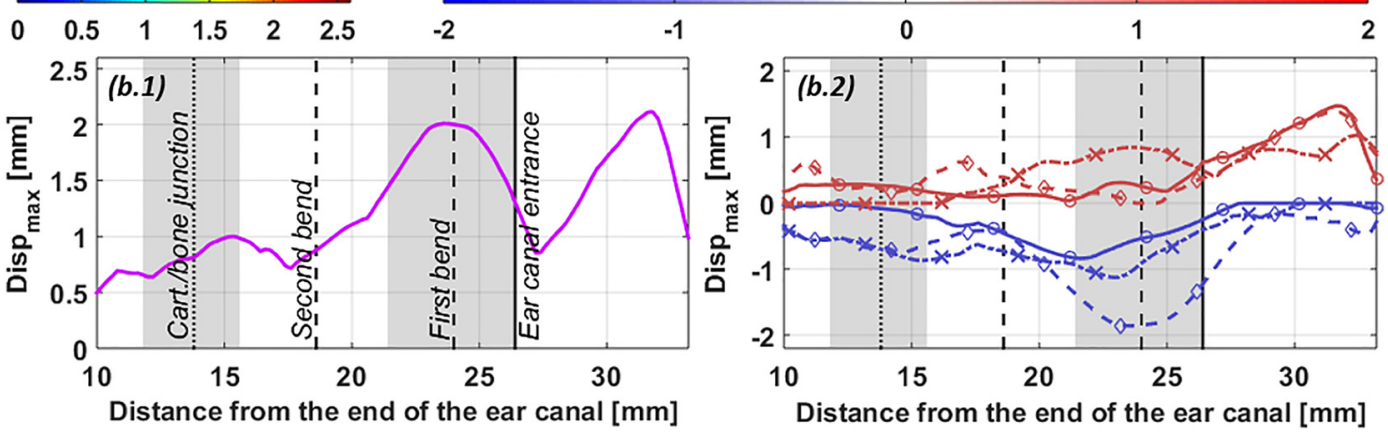

FIG. 8. (Color online) Displacement of the left earcanal occluded by the premolded earplug. (a) Polar plots and (b) maximum values for (a.1) and (b.1) the magnitude, (a.2) and (b.2) (solid-circle lines) medial/lateral (inward/outward), (a.3) and (b.2) (dashed-diamond lines) posterior/anterior (backward/forward) and (a.4) and (b.2) (dotted/dashed-cross lines) inferior/superior (downward/upward) components of the displacement. 


\section{Push-to-fit earplugs}

The push-to-fit earplug mainly deforms the earcanal walls in one restricted location [see Figs. 7(a.1) and 7(b.1)]. This local deformation can be explained by the shape of the earplug itself, which is a thin rigid plastic stem ended by a spherical foam head.

From the entrance of the concha to the entrance of the earcanal, the plastic stem of the earplug can interact with the concha but deforms only slightly this region in the case of the left ear [see Fig. 7(a.1)].

Between the two bends, the regions of maximum displacement magnitude are located just before the second bend in the superior/posterior and inferior/anterior part of the earcanal [see Fig. 7(a.1)]. The main directions of these displacements are backward/upward and forward/downward, respectively [see Figs. 7(a.3) and 7(a.4)] and the maximum displacement magnitude in these regions is equal to $1.8 \mathrm{~mm}$ [see Fig. 7(b.1)]. It can also be noticed that the superior/posterior part of the earcanal is pulled outward and the inferior/anterior one is pushed inwards [see Fig. 7(a.2)].

From the second bend to the plane located at $10 \mathrm{~mm}$ from the tip of the eardrum, the push-to-fit earplug does not deform the earcanal walls in its current insertion depth since the maximum displacement modulus is close to the minimum accuracy level defined in Sec. II E [see Fig. 7(b.1)].

\section{Premolded earplugs}

The premolded earplug locally deforms the earcanal in several locations due to its outer tip and its three flanges.

From the entrance of the concha to the entrance of the earcanal, the largest flange stays outside of the earcanal [see Fig. 1(b.4)] and does not deform the base of the concha [see Fig. 8(a.1)]. However, the tragus is deformed by the outer tip of the earplug stem [see Fig. 8(a.1)] and the maximum displacement magnitude for this region is $2.1 \mathrm{~mm}$ [see Fig. 8(b.1)].

Between the two bends, the second flange of the premolded earplug mainly deforms two regions: (i) the superior/ posterior part of the middle of the first bend [see Fig. 8(a.1)], which is deformed backward/upward [see Figs. 8(a.3) and 8(a.4)]. The amplitude of this maximum displacement is about $2 \mathrm{~mm}$ [see Fig. 8(b.1)]. (ii) The superior/anterior part of the middle of the first bend is deformed backward/downward [see Figs. 8(a.3) and 8(a.4)]. The maximum displacement of this second region is smaller than the displacement of the superior/posterior region [see Fig. 8(a.1)] and its amplitude is about $1.6 \mathrm{~mm}$.

From the second bend to the plane located at $10 \mathrm{~mm}$ from the tip of the eardrum, the third flange of the premolded earplug deforms the superior part of the entrance of the cartilage/bone junction [see Figs. 8(a.1) and 8(b.1)]. In this region, the maximum displacement magnitude is about $1 \mathrm{~mm}$. The direction of this displacement is difficult to evaluate since its amplitude is close to the minimum accuracy level defined in Sec. II E.

\section{B. Differences observed on the right ear}

As mentioned previously, similar trends are observed between the displacement computed for the left and right ear. However, some differences occur between the two occluded ears in some specific regions. These differences are presented in this section and discussed in Sec. IV using the magnitude of the displacement along the right earcanal and the amplitude of its components in each anatomical direction, presented in Figs. 9, 10, 11, and 12.

\section{Custom molded earplug}

For the custom molded earplug, only small differences can be observed between the left (see Fig. 5) and right ear
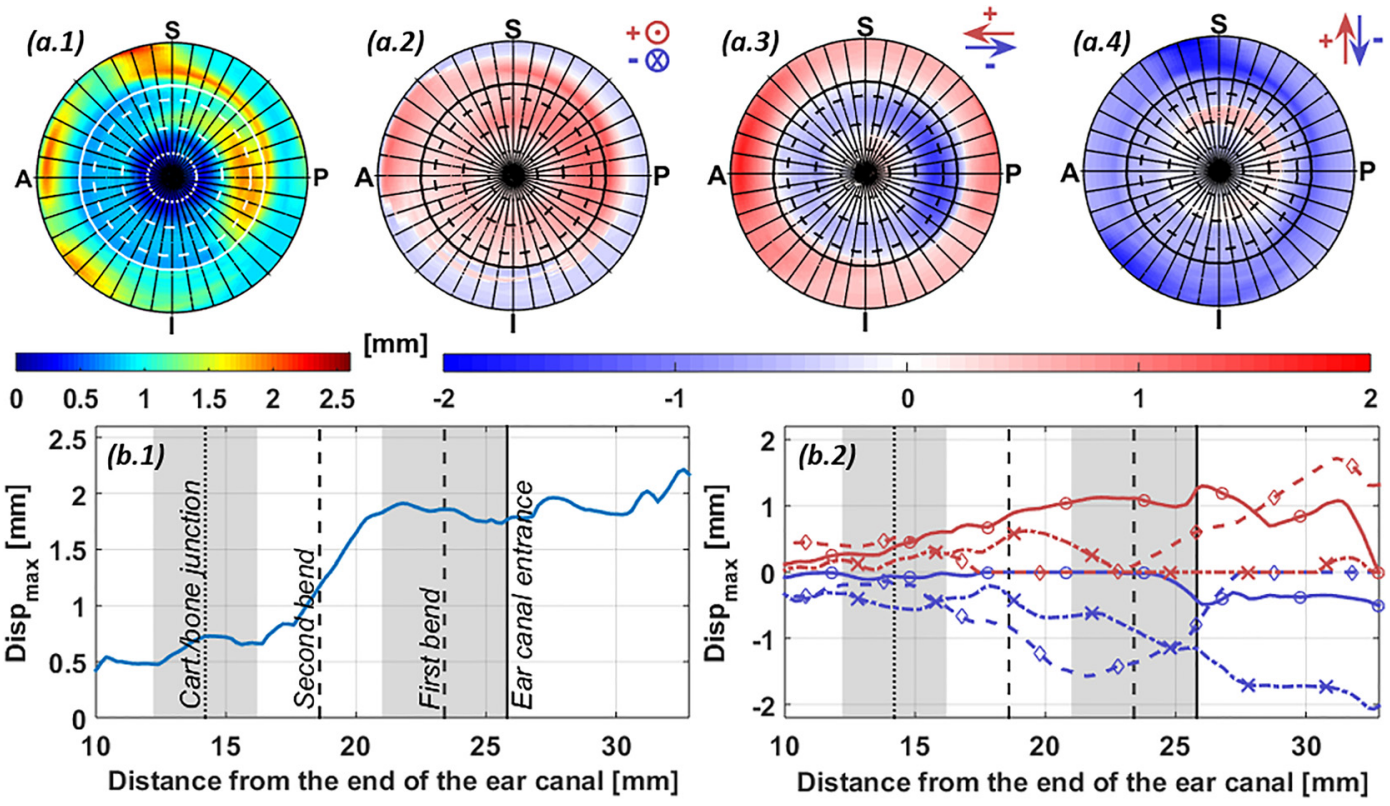

FIG. 9. (Color online) Displacement of the right earcanal occluded by the custom molded earplug. (a) Polar plots and (b) maximum values for (a.1) and (b.1) the magnitude, (a.2) and (b.2) (solid-circle lines) medial/lateral (inward/outward), (a.3) and (b.2) (dashed-diamond lines) posterior/anterior (backward/forward) and (a.4) and (b.2) (dotted/dashed-cross lines) inferior/superior (downward/upward) components of the displacement. 

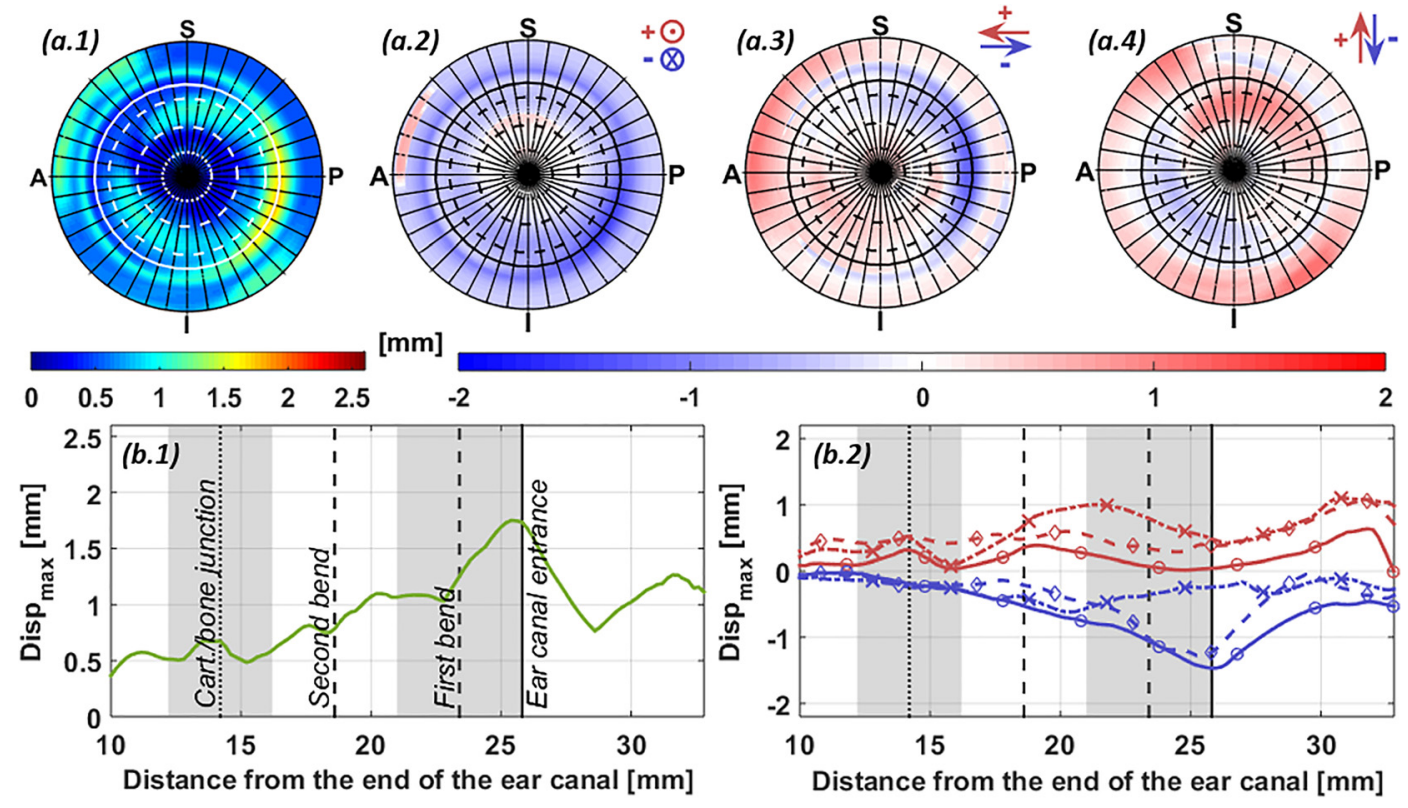

FIG. 10. (Color online) Displacement of the right earcanal occluded by the roll-down foam earplug. (a) Polar plots and (b) maximum values for (a.1) and (b.1) the magnitude, (a.2) and (b.2) (solid-circle lines) medial/lateral (inward/outward), (a.3) and (b.2) (dashed-diamond lines) posterior/anterior (backward/forward) and (a.4) and (b.2) (dotted/dashed-cross lines) inferior/superior (downward/upward) components of the displacement.

(see Fig. 9). The main difference is that the maximum displacement magnitude is smaller for the right ear than for the left ear.

\section{Roll-down foam earplug}

Unlike the left ear, the tragus of the right ear is slightly deformed whereas the posterior part of the base of the concha is largely deformed [see Fig. 10(a.1)]. The corresponding displacement occurs inward [see Fig. 10(a.2)] and backward [see Fig. 10(a.3)]. Another difference compared to the left ear is that the roll-down foam earplug globally pushes the right earcanal walls inward since almost all the earcanal displacement is negative in Fig. 10(a.2). Unlike the left ear, the roll-down foam earplug does not seem to deform the cartilage/bone junction of the right earcanal since the magnitude of the maximum displacement in this region [see Fig. 10(b.1)] is close to the minimum accuracy level described in Sec. II E.

\section{Push-to-fit earplug}

The main difference between the displacement computed for both ears occluded by the push-to-fit earplug is that
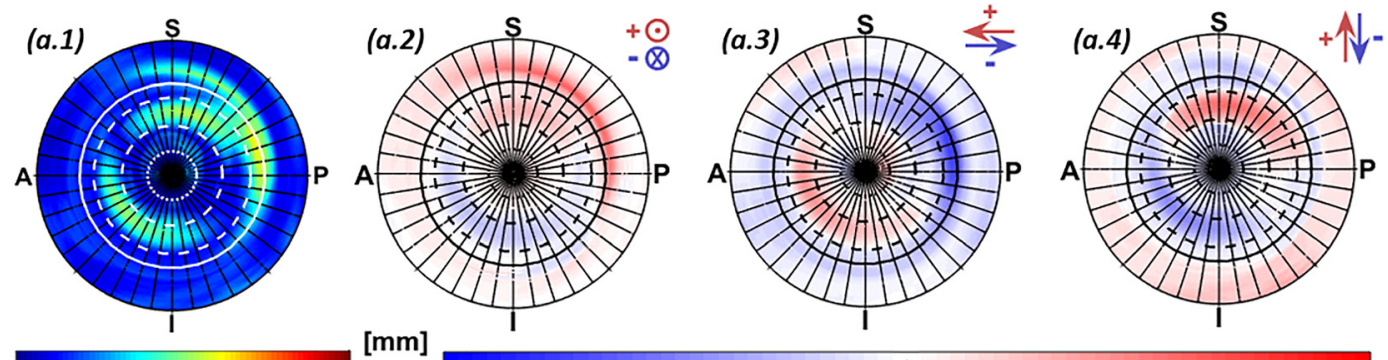

[mm]
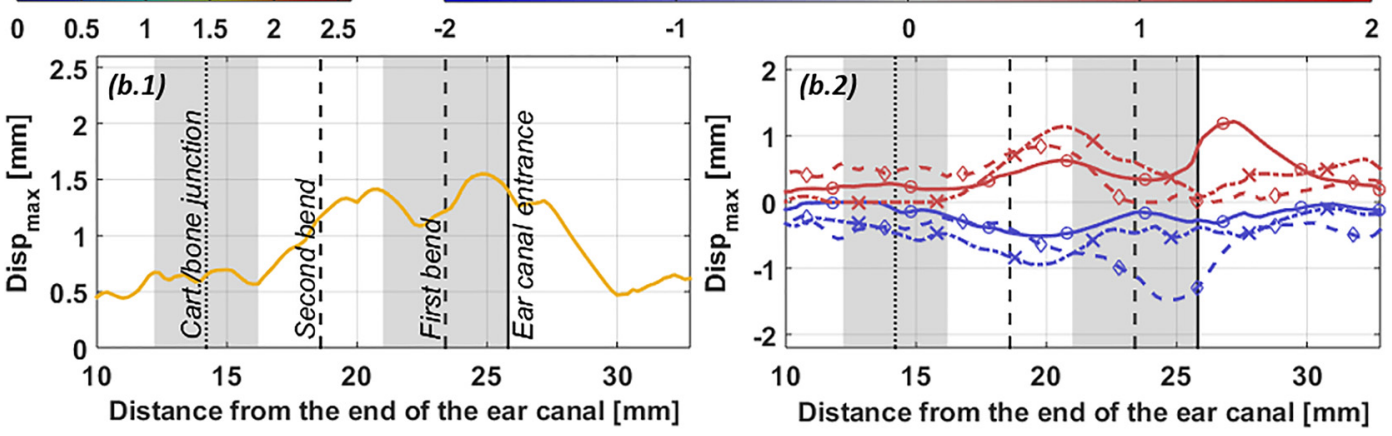

FIG. 11. (Color online) Displacement of the right earcanal occluded by the push-to-fit earplug. (a) Polar plots and (b) maximum values for (a.1) and (b.1) the magnitude, (a.2) and (b.2) (solid-circle lines) medial/lateral (inward/outward), (a.3) and (b.2) (dashed-diamond lines) posterior/anterior (backward/forward) and (a.4) and (b.2) (dotted/dashed-cross lines) inferior/superior (downward/upward) components of the displacement. 

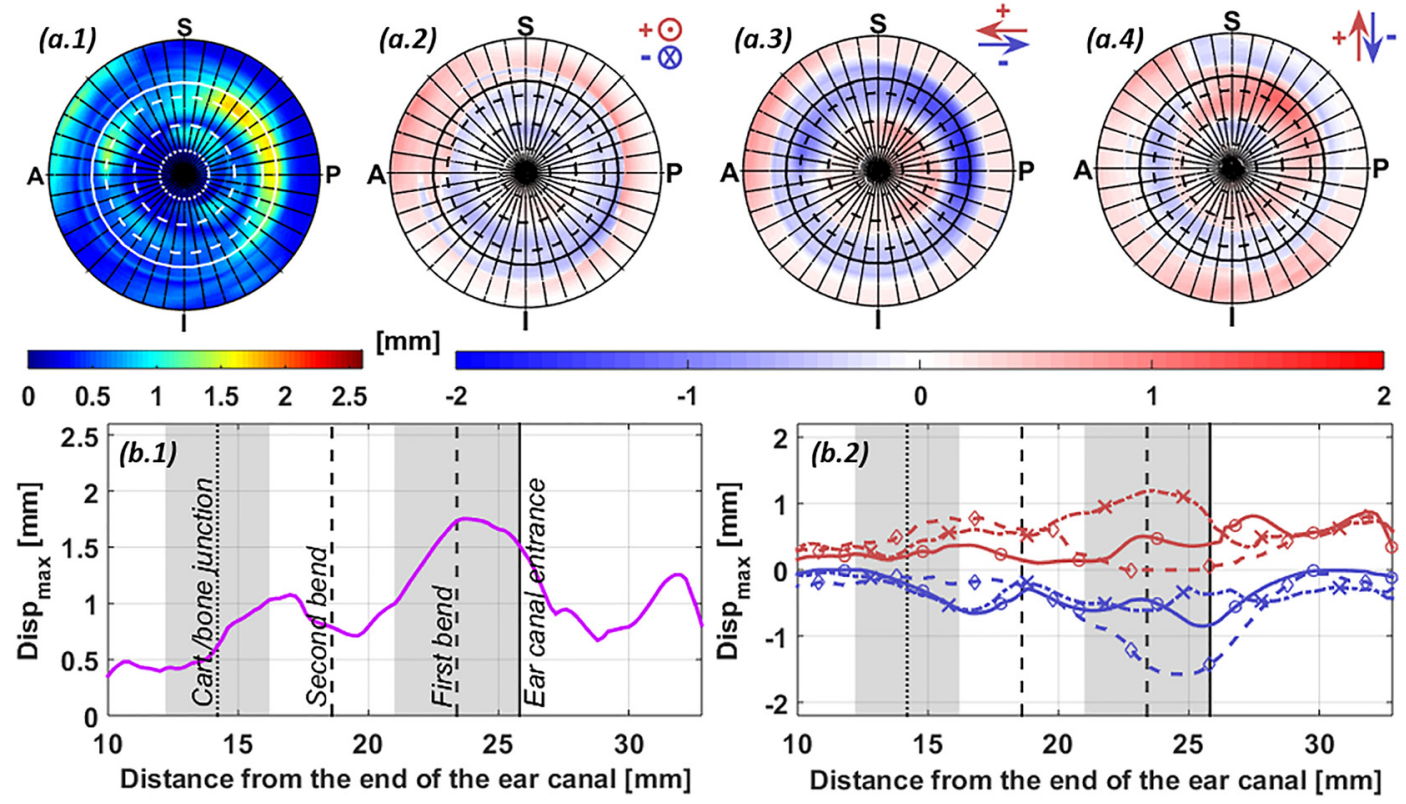

FIG. 12. (Color online) Displacement of the right earcanal occluded by the premolded earplug. (a) Polar plots and (b) maximum values for (a.1) and (b.1) the magnitude, (a.2) and (b.2) (solid-circle lines) medial/lateral (inward/outward), (a.3) and (b.2) (dashed-diamond lines) posterior/anterior (backward/forward) and (a.4) and (b.2) (dotted/dashed-cross lines) inferior/superior (downward/upward) components of the displacement.

the tip of the rigid plastic stem of the right earplug deforms the superior/posterior part of the base of the concha [see Fig. 11(a.1)] outward [see Fig. 11(a.2)] unlike the left ear. The stem of the earplug also deforms the posterior part of the earcanal entrance [see Fig. 11(a.1)] backward [see Fig. 11(a.3)]. Amplitudes of the corresponding maximum displacements are about 1.3 [see Fig. 11(b.2)] and $1.5 \mathrm{~mm}$ [see Fig. 11(b.2)].

\section{Premolded earplug}

Like for the case of the roll-down foam earplugs, the right premolded earplug applies a lower deformation on the tragus than the left earplug [see Figs. 8(a.1) and 12(a.1)]. It is visible in Figs. 1(b.4) and 1(c.4) that the insertion orientation of these two earplugs is different. The magnitude of the maximum displacement due to the outer tip of the premolded earplug inserted in the right ear is equal to $1.2 \mathrm{~mm}$ [see Fig. 12(b.1)]. After the second bend, the right ear displacement is also different from the left one since not only the superior part of the earcanal is deformed but also its inferior/posterior part [see Fig. 12(a.1)].

\section{DISCUSSION}

The results presented in Sec. III are discussed here. First, the influence of the earcanal geometry and earplug shape and insertion on the computed displacement is pointed out. Then, the trends observed for both the left and right ears are discussed. Finally, overall remarks on the method are given.

\section{A. Effect of the earcanal geometry}

It should be noted that the geometry of the participant's ears has important effects on the results obtained for the computed displacement. In this study, the magnitude of the displacement is globally smaller for the right ear than for the left ear of the participant (see Figs. 5, 6, 7, 8 and 9, 10, $11,12)$. This is explained by the fact that the left earcanal has an overall diameter smaller than the right one (data not shown). Thus, small differences between the left and right ear might be explained by the geometry of each ear.

However, the difference between the two earcanals of the participant is also an advantage for the validation of the proposed method. Since the two earcanals of the participant are different and four different earplugs were investigated in this study, an equivalent number of eight configurations were used to assess the displacement of the earcanal resulting in the observation of various kinds of displacements with various amplitudes and in various locations of the earcanal. This number can be considered as large enough to have confidence in the proposed method to estimate the earcanal displacement in most of the human earcanal.

\section{B. Effect of the earplug shape and insertion}

The shape and the insertion of earplugs are also two important parameters which can greatly affect the displacement of the earcanal walls. This can be illustrated considering the left and right ear of the participant occluded by the custom molded earplugs. As mentioned in Sec. III B 1, small differences are observed in the results between the left (see Fig. 5) and right ear (see Fig. 9) in this occlusion case. These differences can be explained by the dissimilarity between geometries of the left and right earcanal, but also by the fact that the earplug shapes were manually carved and smoothed out by the manufacturer during the manufacturing finishing stage. Thus, the final shapes of the custom earplugs may differ from the geometry of the earcanals and might deform them in a different manner for the left and right ears. The insertion of the custom molded earplugs is determined by their shapes. Since the length of the 
left and right custom molded earplugs is similar, the part of the earcanal which is deformed is almost the same for the left and right ear.

The initial shape of the other earplugs (roll-down foam, push-to-fit, and premolded) does not change between left and right ear. However, their insertion may be different. For example, Figs. 1(b.2) and 1(c.2) show that the right rolldown foam earplug was not inserted exactly in the same way as the left earplug. Thus, the displacement of the earcanal walls is not the same for each ear [see Figs. 6(b.1) and 10(b.1)].

Clear-sighted readers would have noticed that neither hearing aids nor earbuds are tested in this study. However, the shapes of these in-ear device types can be compared to the shapes of the earplugs tested. For example, hearing aids and custom molded earplugs have similar shapes since their manufacturing process both uses ear impressions. Some earbuds have similar shapes as the tested premolded earplugs since flanges are commonly used on earbuds.

Finally, the relevance of measuring the displacement of the earcanal due to the insertion of earplugs for a single participant is discussed here. It is clear that the results presented in this paper cannot be generalized or used to conclude on the earcanal displacement due to the insertion of a given earplug in the human earcanal. If some trends can be observed here for the different types of earplugs, the estimated displacement is always closely related to the geometry of the user's earcanal, to the characteristics of the tissues surrounding it and to the shape and insertion of earplugs. Thus, even for a specific earplug, the displacement can be different from one subject to the other since all human earcanals are different. In order to identify effective trends about the displacement due to in-ear devices, future works should investigate this method with a broader range of participants.

\section{Noticeable deformed regions of the earcanal}

From the entrance of the concha to the entrance of the earcanal, the anterior region of the outer part, corresponding to the tragus, is often deformed by earplugs with an outward/ forward displacement. This displacement is due to the outer tip of earplugs, which is either large for custom molded and roll-down foam earplugs or oriented in the tragus direction for other earplugs. The posterior part of the junction between the base of the concha and the entrance of the earcanal is also frequently deformed. But the corresponding displacement seems to be more dependent on how earplugs are inserted.

Between the two bends, and for roll-down foam and push-to-fit earplugs, the regions of maximum displacements occur in the superior/posterior and inferior/anterior parts of the earcanal and the displacement of these two regions is respectively upward/backward and downward/ forward. These preferred directions may be explained by the fact that, between the two bends, the cross section of the participant's earcanal is not circular but ellipsoidal with its minor axis in the superior/posterior-inferior/anterior direction (see Fig. 13). Thus, the roll-down foam earplugs and the foam part of push-to-fit earplugs can easily expand

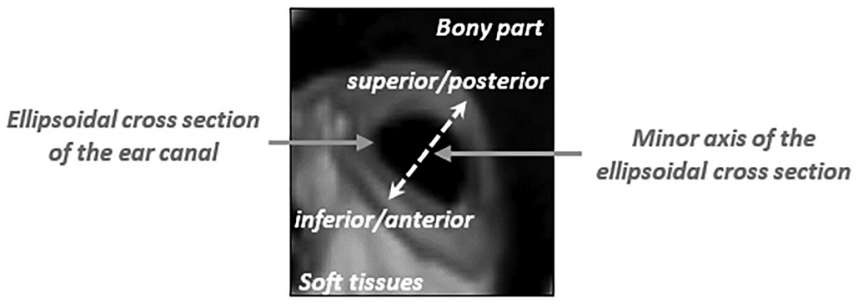

FIG. 13. Ellipsoidal cross section of the right earcanal between the two bends. The double dashed arrow indicates the minor axis of the ellipsoidal cross section in the superior/posterior-inferior/anterior direction.

in the direction of the major axis of the ellipsoidal cross section of the earcanal leading to a larger deformation in the direction of the minor axis of the ellipse.

\section{Representation of the displacement}

The relevance of displaying the maximum amplitudes (both positive and negative) of the displacement components along the earcanal can be difficult to grasp. However, these representations offer useful information to better understand how earplugs deform the earcanal. For example, maximum amplitudes obtained simultaneously for opposite directions [see dashed-diamond lines in Fig. 7(b.2) for example] indicate that the earplug pushes on each side of the earcanal walls as if it was expanding in the earcanal [see Fig. 14(a)]. When the displacement amplitude is maximum in one direction and equal to zero in the opposite direction [see dasheddiamond lines in Fig. 5(b.2) for example], the earplug deforms the earcanal in only one direction in the

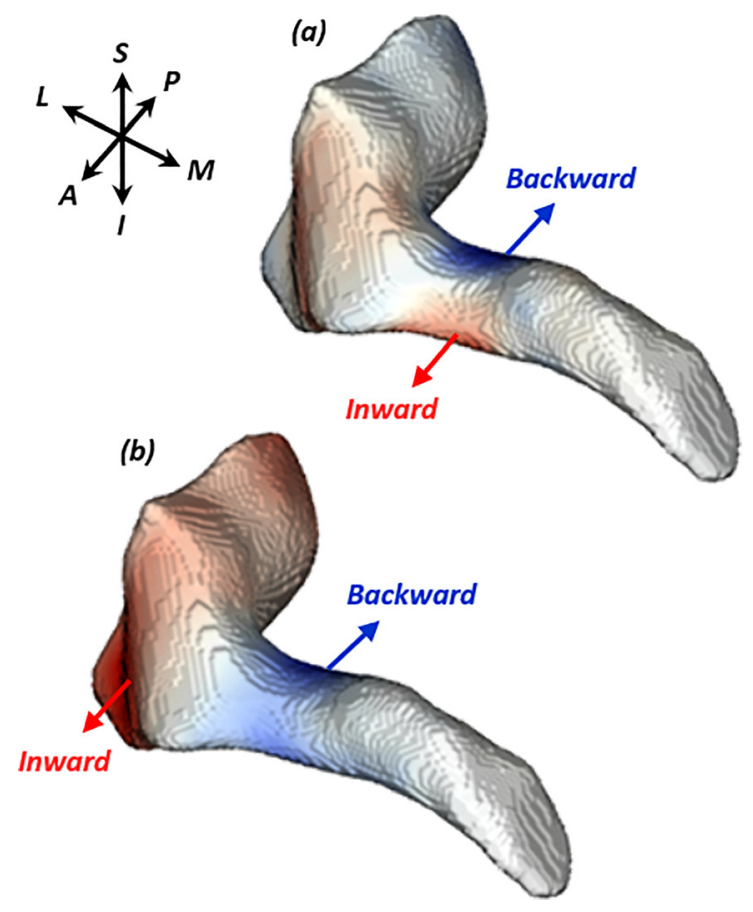

FIG. 14. (Color online) Projection on the walls of the left earcanal (flipped in the medial/lateral direction) of the posterior/anterior component of the displacement for the (a) push-to-fit and (b) custom molded earplugs. Arrows indicate the direction for regions of maximum (both positive and negative) displacement. The system of coordinates recalls the anatomical directions with (S) superior, (I) inferior, (A) anterior, (P) posterior, (L) lateral, and (M) medial. 

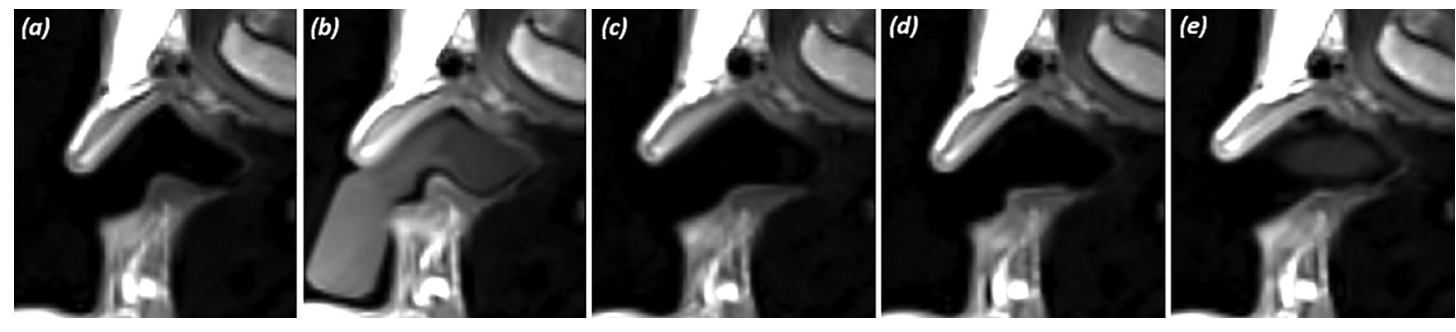

FIG. 15. MR images of the earcanal of the subject (a) unoccluded and occluded by (b) the custom molded, (c) the roll-down foam, (d) the push-to-fit, and (e) the premolded earplugs.

corresponding cross section [see Fig. 14(b)]. These two examples are illustrated in Fig. 14 using three-dimensional projections of the displacement in the posterior/anterior direction on the walls of the left earcanal flipped in the medial/lateral direction.

Figure 14 shows that if the displacement induced by the push-to-fit earplug seems intuitive [see Fig. 14(a)], the displacement due to the custom molded earplug is not [see Fig. 14(b)]. Indeed, as the custom molded earplug is considered as rigid, its motion in the axial plane is a rotation around an axis located in the middle of the first bend of the earcanal leading to an inward and backward displacement of its outer and inner tips, respectively. This information could be useful to earplug manufacturers to improve the fitting characteristics of earplugs. Another example of unexpected direction of the displacement is given by Figs. 5(a.2) and 5(a.4), where the superior/posterior part of the base of the concha moves outward/downward. This displacement might be due to a complex interaction between the concha and the earplug and cannot be observed using only the maximum amplitude of the displacement presented in Fig. 5(a.1).

In order to improve the relevance of the proposed representations (polar plots and maximum displacement along the earcanal), the displacement of the earcanal walls due to the insertion of earplug could be plotted along the center axis of the earcanal and not along a straight line normal to sagittal planes (Stinson and Lawton, 1989). Using the center axis of the earcanal would allow a better localization of the first and second bends of the earcanal using, for example, the curvature or the torsion of the canal (Delnavaz and Voix, 2013).

\section{CONCLUSION}

This paper proposes to investigate the possibilities offered by the method described in Benacchio et al. (2018) to estimate the earcanal displacement due to the insertion of in-ear devices using magnetic resonance images taken in vivo on a human subject. First, the earcanal open and occluded by an in-ear device is imaged using an adapted MRI sequence. Then, the method relies on rigid and deformable registrations of the MR images obtained to compute the displacement of the earcanal walls. In this study, the displacement induced by four different types of in-ear devices (custom molded, roll-down foam, push-to-fit, and premolded earplugs) were investigated for each ear of a participant. Results were displayed using polar plots of the displacement magnitude and of its components in each direction or line plots of their maximum value along the earcanal (perpendicularly to sagittal planes). Thanks to these graphical representations, it was possible to observe the location and the amplitude of maximum displacement along the earcanal. Polar representations of the displacement components provided the direction in which these regions move and allow for identifying how earplugs deform the earcanal (expansion, rigid motion in one direction). In spite of small differences due to the geometry of the left and right earcanals and the shape and insertion of the earplugs, the results show a reasonable similarity between the displacements computed for the participant's left and right ears when they are occluded by the same earplug type. Thus, the precision of the proposed method allows for investigating quantitatively the effects of geometrical or physical features of the earcanal or of in-ear devices on comfort aspects whereas these features were only qualitatively studied in the past.

However, the results cannot be generalized since they were obtained from only a single participant. But the diversity of results obtained for the eight different configurations (two earcanals and four different earplugs) investigated in this study suggests that the proposed method is relevant to estimate the displacement in most human earcanals. Future studies must investigate displacements due to other in-ear devices and be computed for a large panel of participants to obtain trends on how a specific in-ear device family deforms the earcanal. These results could be used by hearing protector or hearing aid manufacturers to improve the comfort aspects of their devices. Displacements could also be used in numerical simulations to understand how the deformation of the earcanal affect acoustical comfort aspects of hearing protectors and hearing aids such as sound attenuation or occlusion effect.

\section{ACKNOWLEDGMENTS}

The authors would like to thank the Laboratoire Auditif Laviolette from Trois-Rivières for the custom earplugs and the institut de recherche Robert Sauvé en santé et sécurité du travail (IRSST) and MITACS for the funding of this research (Grant No. 2016-0020).

\section{APPENDIX: MR IMAGES OF THE OPEN AND OCCLUDED EARCANAL}

This figure shows an axial view of the earcanal of the subject with an orientation different from that presented in Fig. 2. Figure 15(a) shows the subject's open earcanal and its earcanal occluded with [Fig. 15(b)] the custom molded, [Fig. 15(c)] the 
roll-down foam, [Fig. 15(d)] the push-to-fit and [Fig. 15(e)] the premolded earplugs. Compared to Fig. 2(b), Fig. 15(b) shows the custom molded earplug in a single section.

It can be seen that the custom molded earplug does not make a full contact with all portions of the earcanal wall. This does not mean that this earplug does not create an efficient acoustic seal since it might be ensured at other locations of the earcanal. Moreover, it is recalled here that the custom molded earplug manufacturer has been asked to manufacture a "large" and "long" earplug. The underlying shape modifications may have created some unexpected large dimensions of the earplug leading to unusual displacement of the earplug in the earcanal and maybe some abnormal loss of contact between the earplug and the earcanal wall. Since they are made with foam and/or plastic, the rolldown foam and the push-to-fit earplugs are not visible on the MR images [see Figs. 15(c) and 15(d)]. However, the displacement resulting from their insertion is still clearly observable. As the premolded earplug is made with silicone, it is observable in Fig. 15(e), but not very clearly due to its complex shape compressed in the subject's earcanal.

${ }^{1}$ ANTs documentation: https://sourceforge.net/projects/advants/files/ Documentation/ (Last viewed September 16, 2019).

Avants, B. B., Tustison, N. J., Song, G., Cook, P. A., Klein, A., and Gee, J. C. (2011). "A reproducible evaluation of ANTs similarity metric performance in brain image registration," Neuroimage 54, 2033-2044.

Baker, A. T., Lee, S. H., and Mayfield, F. (2010). "Evaluating hearing protection comfort through computer modeling," in Proceedings of the 2010 Simulia Customer Conference, May 25-27, Providence, RI, pp. 1-15.

Benacchio, S., Doutres, O., Le Troter, A., Varoquaux, A., Wagnac, E., Callot, V., and Sgard, F. (2018). "Estimation of the earcanal displacement field due to in-ear device insertion using a registration method on a human-like artificial ear," Hear. Res. 365, 16-27.

Berger, E. (2013). "'Calibrating' the insertion depth of roll-down foam earplugs," Proc. Mtgs. Acoust. 19, 040002.

Brown-Rothwell, D. J. (1986). "The comfort of earplugs: Basis for a descriptive model," M.D. thesis, University of Southampton, Southampton, UK.

Casali, J. G., Lam, S. T., and Epps, B. W. (1987). "Rating and ranking methods for hearing protector wearability," Sound Vib. 21(12), 10-18.

Darkner, S., Jonsson, S., and Sommer, S. (2017). "In vivo study of the human earcanal using contrast-enhanced MRI," in Proceedings of the 25th Annual Meeting of the International Society for Magnetic Resonance in Medicine, April 22-27, Honolulu, HI, pp. 1-3.

Darkner, S., Larsen, R., and Paulsen, R. R. (2007). "Analysis of deformation of the human ear and canal caused by mandibular movement," in Medical Image Computing and Computer-Assisted Intervention-MICCAI 2007, Lecture Notes in Computer Science, Vol. 4792, edited by N. Ayache, S. Ourselin, and A. Maeder (Springer, Berlin-Heidelberg), pp. 101-108.

Darkner, S., Sabuncu, M. R., Golland, P., Paulsen, R. R., and Larsen, R. (2008). "Analysis of surfaces using constrained regression models," in Proceedings of 11th International Conference on Medical Image Computing and Computer-Assisted Intervention-MICCAI 2008, Lecture Notes in Computer Science, Vol. 5241, edited by D. Metaxas, L. Axel, G. Fichtinger, and G. Székely (Springer, Berlin-Heidelberg), Part I, pp. 842-849.
Delnavaz, A., and Voix, J. (2013). "Ear canal dynamic motion as a source of power for in-ear devices," J. Appl. Phys. 113, 064701.

Doutres, O., Sgard, F., Terroir, J., Perrin, N., Jolly, C., Gauvin, C., and Negrini, A. (2019). "A critical review of the literature on comfort of hearing protection devices: Definition of comfort and identification of its main attributes for earplug types," Int. J. Audiol. (published online).

Egolf, D. P., Nelson, D. K., Howell, H. C. III, and Larson, V. D. (1993). "Quantifying ear-canal geometry with multiple computer-assisted tomographic scans," J. Acoust. Soc. Am. 93(5), 2809-2819.

Gerges, S. N. Y., and Casali, J. G. (2007). "Hearing protectors," in Handbook of Noise and Vibration Control (John Wiley \& Sons, Inc., New York), Chap. 31, pp. 364-376.

Grenness, M. J., Osborn, J., and Weller, W. L. (2002). "Mapping earcanal movement using area-based surface matching," J. Acoust. Soc. Am. 111(2), 960-971.

Inoue, J., Yamashita, Y., Horie, S., Kawanami, S., and Takahashi, K. (2011). "Earplug fitting and the computed tomography," in Proceedings of Inter-Noise 2011, September 4-7, Osaka, Japan, pp. 2871-2880.

Kochkin, S. (2000). "MarkeTrak V: "Why my hearing aids are in the drawer': The consumers' perspective," Hear. J. 53(2), 34-41.

Oliveira, R. J. (1997). "The active earcanal," J. Am. Acad. Audiol. 8, 401-410.

Oliveira, R., Babcock, M., Venem, M., Hoeker, G., Parish, B., and Kolpe, V. (2005). "The dynamic earcanal and its implications," Hear. Rev., available at http://www.hearingreview.com/2005/02/the-dynamic-ear-canaland-its-implications/.

Oliveira, R., Hammer, B., Stillman, A., Holm, J., Jons, C., and Margolis, R. H. (1992). "A look at earcanal changes with jaw motion," Ear Hear. 13(6), 464-466.

Paulsen, R., Larsen, R., Nielsen, C., Laugesen, S., and Ersboll, B. (2002). "Building and testing a statistical shape model of the human earcanal," in Medical Image Computing and Computer-Assisted InterventionMICCAI 2002, Lecture Notes in Computer Science, Vol. 2489, edited by T. Doi and R. Kikinis (Springer, Berlin-Heidelberg), Part II, pp. 373-380.

Pirzanski, C. (2006). "Earmolds and hearing aid shells: A tutorial Part 2: Impression-taking techniques that result in fewer remakes," Hear. Rev., available at http://www.hearingreview.com/article/earmolds-and-hearingaid-shells-a-tutorial-part-2-impression-taking-techniques-that-result-infewer-remakes/.

Pirzanski, C., and Berge, B. (2004). "If you blame buffing for bad fittings, you've probably given the wrong impression," Hear. J. 57(2), 40-45.

Pirzanski, C., Chasin, M., Klenk, M., Maye, V., and Purdy, J. (2000). "Attenuation variables in earmolds for hearing protection devices," Hear. J. 53(6), 44-49.

Rasetshwane, D. M., and Neely, S. T. (2011). "Inverse solution of ear-canal area function from reflectance," J. Acoust. Soc. Am. 130(6), 3873-3881.

Salvi, R., and Sheppard, A. (2018). "Is noise in the MR imager a significant risk factor for hearing loss?," Radiology 286(2), 609-610.

Stinson, M. R., and Lawton, B. W. (1989). "Specification of the geometry of the human earcanal for the prediction of sound-pressure level distribution," J. Acoust. Soc. Am. 85(6), 2492-2503.

Terroir, J., Doutres, O., and Sgard, F. (2017). "Toward a 'global' definition of the comfort of earplugs," in Proceedings of INTER-NOISE and NOISECON Congress and Conference (InterNoise17), August 27-30, Hong Kong, China, pp. 108-114.

Wheeler, D. E., and Glorig, A. (1956). "The industrial hygienist and ear protection," Noise Control 2, 45-72.

Yu, J. F., Lee, K. C., Wang, R. H., Chen, Y. S., Fan, C. C., Peng, Y. C., Tu, T. H., Chen, C. I., and Lin, K. Y. (2015). "Anthropometry of external auditory canal by non-contactable measurement," Appl. Ergon. 50, 50-55.

Zemplenyi, J., Gilman, S., and Dirks, D. (1985). "Optical method for measurement of earcanal length," J. Acoust. Soc. Am. 78(6), 2146-2148. 